\title{
Complications after transsphenoidal surgery for patients with Cushing's disease and silent corticotroph adenomas
}

\author{
Timothy R. Smith, MD, PhD, MPH, M. Maher Hulou, MD, Kevin T. Huang, MD, Breno Nery, MD, \\ Samuel Miranda de Moura, MD, David J. Cote, BS, and Edward R. Laws, MD
}

Department of Neurosurgery, Brigham and Women's Hospital, Boston, Massachusetts

OBJECT The purpose of this study was to describe complications associated with the endonasal, transsphenoidal approach for the treatment of adrenocorticotropic hormone (ACTH)-positive staining tumors (Cushing's disease [CD] and silent corticotroph adenomas [SCAs]) performed by 1 surgeon at a high-volume academic medical center.

METHODS Medical records from Brigham and Women's Hospital were retrospectively reviewed. Selected for study were 82 patients with CD who during April 2008-April 2014 had consecutively undergone transsphenoidal resection or who had subsequent pathological confirmation of ACTH-positive tumor staining. In addition to demographic, patient, tumor, and surgery characteristics, complications were evaluated. Complications of interest included syndrome of inappropriate antidiuretic hormone secretion, diabetes insipidus (DI), CSF leakage, carotid artery injury, epistaxis, meningitis, and vision changes.

RESULTS Of the 82 patients, 68 (82.9\%) had CD and $14(17.1 \%)$ had SCAs; 55 patients were female and 27 were male. Most common ( $n=62$ patients, $82.7 \%$ ) were microadenomas, followed by macroadenomas $(n=13,14.7 \%)$. A total of $31(37.8 \%)$ patients underwent reoperation. Median follow-up time was 12.0 months (range 3-69 months). The most common diagnosis was ACTH-secreting $(n=68,82.9 \%)$, followed by silent tumors/adenomas $(n=14,17.1 \%)$. ACTH hyperplasia was found in 8 patients $(9.8 \%)$. Of the 74 patients who had verified tumors, $12(16.2 \%)$ had tumors with atypical features.

The overall (CD and SCA) rate of minor complications was $35.4 \%$; the rate of major complications was $8.5 \%(n=7)$. All permanent morbidity was associated with DI $(n=5,6.1 \%)$. In 16 CD patients $(23.5 \%)$, transient DI developed. Transient DI was more likely to develop in CD patients who had undergone a second operation (37.9\%) than in those who had undergone a first operation only $(12.8 \%, p<0.05)$. Permanent DI developed in 4 CD patients $(5.9 \%)$ and 1 SCA patient (7.1\%). For $1 \mathrm{CD}$ patient, intraoperative carotid artery injury required endovascular sacrifice of the injured artery, but the patient remained neurologically intact. For another CD patient, aseptic meningitis developed and was treated effectively with corticosteroids. One CD patient experienced major postoperative epistaxis requiring another operative procedure to achieve hemostasis. For 2 CD patients, development of sinus mucoceles was managed conservatively. For 1 SCA patient, an abdominal wound dehisced at the fat graft site. No patients experienced postoperative CSF leakage, visual impairment, or deep vein thrombosis.

CONCLUSIONS Transsphenoidal surgery is the treatment of choice for patients with CD and other ACTH-positive staining tumors. Recent advances in endoscopic technology and increasing surgeon comfort with this technology are making transsphenoidal procedures safer, faster, and more effective. Serious complications are uncommon and can be managed successfully.

http://thejns.org/doi/abs/10.3171/2014.10.FOCUS14705

KEY WORDS endoscopic; endonasal; transsphenoidal; complications; Cushing's disease

ABBREVIATIONS ACTH = adrenocorticotropic hormone; $\mathrm{CD}=$ Cushing's disease; $\mathrm{DI}=$ diabetes insipidus; $\mathrm{GTR}$ = gross-total resection; ICA = internal carotid artery; SCA = silent corticotroph adenoma; SIADH = syndrome of inappropriate antidiuretic hormone secretion.

SUBMITTED October 7, 2014. ACCEPTED October 16, 2014

INCLUDE WHEN CITING DOI: 10.3171/2014.10.FOCUS14705.

DISCLOSURE The authors report no conflict of interest concerning the materials or methods used in this study or the findings specified in this paper. 
$\mathrm{C}$ USHING's disease (CD) is a hypercortisolemic state caused by the presence of a corticotroph-producing adenoma and accounts for $70 \%-80 \%$ of all cases of Cushing's syndrome in adults. ${ }^{38}$ Less commonly, an adrenocorticotropic hormone (ACTH)-secreting lesion located outside the hypophyseal system causes elevated serum cortisol levels. The most common locations for ACTH production in patients with Cushing's syndrome are the adrenal glands, lungs, liver, or ovaries. . $^{59}$ Cushing's syndrome can also arise iatrogenically, as a consequence of long-term glucocorticoid therapy..$^{14,61}$

Corticotroph-producing adenomas represent approximately $16 \%$ of all surgically resected pituitary tumors. ${ }^{21}$ Of patients with $\mathrm{CD}$, women are more likely to harbor corticotroph-secreting adenomas; reported female-tomale ratios are 3-10:1. ${ }^{34}$ Although corticotroph-secreting adenomas can occur in patients of any age, peak incidence is between the 3rd and 5th decades of life. Delays in CD diagnosis, management, and follow-up are common and lead to increased adverse metabolic complications and death. For optimal patient outcomes, rapid recognition, treatment, and vigilant monitoring are crucial.

If left unchecked, the combined clinical manifestations of CD increase a person's risk for increased illness and/ or death while substantially reducing quality of life. The transsphenoidal approach for resection of corticotrophsecreting adenomas is associated with a high percentage of disease remission. ${ }^{46,55,63}$ After surgical treatment, some patients may experience persistent subclinical CD that remains difficult to detect with routine testing. ${ }^{28}$ Complications (e.g., CSF leakage, deteriorated vision, epistaxis, headaches, and infection) are uncommon but potential adverse events after transsphenoidal operative procedures. ${ }^{41,45,50}$

Silent corticotroph adenomas (SCAs) are defined by physiological cortisol secretion and ACTH-immunopositive staining without the autonomous ACTH secretion found in patients with CD. ${ }^{47,64}$ Unlike CD patients, SCA patients most commonly experience headache, visual field deficits, and subacute pituitary apoplexy. ${ }^{64}$ Patients harboring SCAs do not experience supraphysiological levels of cortisol and therefore are not as prone to the numerous systemic ailments associated with CD. ${ }^{23,44}$ Some authors have reported that patients have increased aggression and that SCAs tend to recur and progress more than CD. ${ }^{20,33}$

In this article, we describe the complications associated with the endonasal, transsphenoidal approach for the treatment of ACTH-positive staining tumors (CD and SCA) performed by 1 surgeon at Brigham and Women's Hospital, a high-volume academic medical center.

\section{Methods}

Of the 681 patients who had undergone transsphenoidal resection at Brigham and Women's Hospital from April 2008 through April 2014, medical records were reviewed for 82 who had either CD or SCA. We included patients with positive ACTH immunohistochemical staining results but without clinical diagnosis of $\mathrm{CD}$. Endocrinologists at the Comprehensive Pituitary Center at the hospital verified the diagnosis of all patients with central
ACTH-dependent CD. All patients underwent endonasal transsphenoidal surgery performed by 1 surgeon (E.R.L.). Samples for laboratory testing were collected from all patients before surgery and on postoperative Days 1, 2, and 7; postoperative Months 3, 6, and 12; and every year thereafter. All patients underwent Gd-enhanced brain MRI for which there were high-resolution thin-cut pituitary sequences and reconstructions in 3 orthogonal planes. These MR images were obtained preoperatively, 3 months postoperatively, and annually thereafter.

Patient records were evaluated for basic demographic information (age, sex) and preoperative presentation (endocrine function, presenting symptoms, and any attempted medical therapy). Also evaluated were imaging characteristics (size, location, cystic nature, degree of invasion of local structures if body CT was used to screen for other sources of ACTH secretion), surgical characteristics (endoscopic vs microscopic procedure; use of fat graft, nasal packing, or lumbar drains), and surgical pathology findings (any atypia noted on histopathological examination, MIB1 labeling index, immunohistochemistry results). Also recorded were laboratory results (serum cortisol, ACTH, other endocrine axes) and data on the patient's postoperative hospital course (length of stay, days spent in the intensive care unit, need for hormone replacement, postoperative endocrine function, extent of resection according to postoperative imaging, need for any adjuvant treatment).

Complications of interest were symptomatic syndrome of inappropriate antidiuretic hormone secretion (SIADH), diabetes insipidus (DI), epistaxis requiring reoperation or readmission, injury to the internal carotid artery (ICA), meningitis, CSF leakage, abdominal wound infection, new visual deficit, postoperative hemorrhage, mucocele formation, and 30-day postoperative readmission for any reason.

Basic patient demographics, preoperative characteristics, and perioperative characteristics were summarized by using counts and percentages for nominal variables and by using means/medians and standard deviations/ranges for continuous variables. Patients were categorized according to sex and further evaluated for substantial difference by sex in terms of tumor size (micro- vs macroadenoma), age, and highest preoperative cortisol level. Records were then examined for postoperative complications. Pathological characteristics (immunohistochemistry findings and MIB1 indices) and postoperative complications were summarized by using counts and percentages or means and standard deviations as appropriate. Tests of significance were determined by using chi-square tests and MantelHaenszel odds ratios for nominal variables, Student t-tests for continuous variables, and ANOVA for continuous variables with more than 2 categories. The data were analyzed by using SPSS version 22 (IBM Inc.). For all analysis, an alpha level of less than 0.05 was considered statistically significant.

\section{Results}

Of the 82 patients with ACTH-positive staining tumors, $68(82.9 \%)$ had CD and $14(17.1 \%)$ had SCA; 55 were women (mean age 42.3, range 8-68 years) and 27 were men (mean age 46.5, range 10-70). Recurrent disease 
developed after surgery for 29 patients: 26 at other institutions and 3 at ours. The mean preoperative serum cortisol level was $22.1 \mu \mathrm{g} / \mathrm{dl}$ (range 18.9-54.4 $\mu \mathrm{g} / \mathrm{dl}$ ) among patients with $\mathrm{CD}$ and $12.7 \mu \mathrm{g} / \mathrm{dl}$ (range $2.3-20.6 \mu \mathrm{g} / \mathrm{dl}$ ) among patients with SCA. The median follow-up time was 12.0 months (range 3-69 months) (Table 1).

\section{Cushing's Disease \\ Presentation}

Among the 68 patients with $\mathrm{CD}$, the most common presenting symptoms and signs were weight gain $(\mathrm{n}=53$, $77.9 \%)$, centripetal fat deposition $(n=42,61.8 \%)$, fatigue $(\mathrm{n}=36,52.9 \%)$, hypertension $(\mathrm{n}=31,45.6 \%)$, skin changes $(n=29,42.6 \%)$, and hair changes $(n=24,35.3 \%)$. Acne was present in 7 patients (10.3\%). Visual disturbance were the presenting symptoms in less than one-quarter of $\mathrm{CD}$ patients $(\mathrm{n}=16,23.5 \%)$. Among 48 female patients, galactorrhea was present in $4(8.3 \%)$, fertility problems in 2 (4.1\%), and dys- or amenorrhea in 19 (39.5\%). Sexual dysfunction was reported by $8 \mathrm{CD}$ patients $(11.8 \%)$; less commonly reported were anxiety $(\mathrm{n}=14,20.6 \%)$, mood changes $(n=20,29.4 \%)$, and cognitive dysfunction $(n=8$, $11.8 \%)$. Cavernous sinus syndrome was uncommon $(\mathrm{n}=2$, $2.9 \%$ ). One CD patient (1.5\%) had signs of pituitary tumor apoplexy (Table 1).

Deficiencies in more than 2 other hormonal axes were found in $6 \mathrm{CD}$ patients $(8.8 \%)$. Most CD patients $(n=45$, $66.1 \%$ ) were receiving treatment for diabetes mellitus, 6 $(8.8 \%)$ were taking thyroid replacement medication, 1 undergoing reoperation was taking growth hormone replacement medication, and another was taking desmopressin for DI (Table 1).

\section{Imaging Characteristics}

Of the 68 patients with $\mathrm{CD}$, most $(\mathrm{n}=60,88.2 \%)$ had microadenomas, 2 (2.9\%) had macroadenomas, and 6 (8.8\%) had no adenomas visible on preoperative brain MR images. Only 2 patients (2.9\%) had suprasellar extension, and $11(16.1 \%)$ had tumors invading the parasellar and/or suprasellar structures (Table 2).

\section{Perioperative Characteristics}

Intraoperatively, an endoscope was used for $97.1 \%$ of $\mathrm{CD}$ patients and a microscope was used for $4.7 \%$ of $\mathrm{CD}$ patients (microscope was used exclusively for only 6 patients). Nasal packing was required in 28 patients (41.2\%), and a lumbar drain was required in 1 patient (1.4\%). An abdominal fat graft was used in 34 patients $(50 \%)$ when a CSF leak was suspected or directly visualized at the time of resection. Gross-total resection (GTR) was achieved in $64 \mathrm{CD}$ patients (94.1\%). Postoperative admission to the intensive care unit was needed by 16 patients, and the average hospital stay was $3.3 \pm 1.0$ days (Table 3 ).

\section{Silent Corticotroph Adenomas \\ Presentation}

Among the 14 patients (17.1\%) with SCA, the mean age was 51.6 years (range 27-70 years), which was older than that of CD patients (mean age 38.7 years). SCAs were present in 7 women and 7 men (50\% each). Fewer SCA patients $(\mathrm{n}=2,14.3 \%)$ than CD patients $(\mathrm{n}=29,42.6 \%)$ underwent surgery for recurrence (Table 1).

The most common presenting signs and symptoms among patients with SCA were headache $(\mathrm{n}=10,71.4 \%)$, visual impairment $(\mathrm{n}=9,64.3 \%)$, hypertension $(\mathrm{n}=6$, $42.9 \%)$, weight gain $(\mathrm{n}=4,28.6 \%)$, and pituitary apoplexy $(\mathrm{n}=4,28.6 \%)$. Sexual dysfunction was present in 3 patients $(21.4 \%)$, cavernous sinus syndrome in $1(7.1 \%)$, and evidence of osteoporosis in 2 (14.3\%) (Table 1).

Preoperative thyroid replacement therapy was being received by 4 SCA patients $(28.6 \%)$ and diabetes mellitus therapy by $8(57.1 \%)$. The mean preoperative serum cortisol level among SCA patients was $12.7 \mu \mathrm{g} / \mathrm{dl}$ (range 2.3-20.6 $\mu \mathrm{g} / \mathrm{dl}$ ). The median follow-up time for patients with SCA was 24.0 months (range 3-69 months) (Table 1).

\section{Imaging Characteristics}

Most patients with SCA $(n=8,57.1 \%)$ had macroadenomas. A tumor with radiographic evidence of tumor invasion was present in 1 patient (7.1\%), cystic components in $1(7.1 \%)$, and suprasellar extension in $2(14.2 \%)$ (Table 2). For no patient with SCA were preoperative MR images of the brain interpreted as normal.

\section{Perioperative Characteristics}

All patients with SCA underwent an endoscopic transsphenoidal operation exclusively $(n=14,100 \%)$. Abdominal fat grafting was performed in 8 patients $(57.1 \%)$, nasal packing in 5 (35.7\%), and placement of a lumbar drain in none. Gross-total resection was achieved in 11 SCA patients (78.6\%). Postoperative admission to the intensive care unit was required by 1 (7.1\%) SCA patient. Average hospital stay was $2.8(\mathrm{SD}=1.1)$ days.

\section{Postoperative Normalization of Serum Cortisol Levels in Patients With CD}

Postoperatively, cortisol levels normalized on the first postoperative day for $72.4 \%$ of patients with recurrent $C D$ tumors and $82.1 \%$ of patients with de novo CD. Cortisol levels normalized on the seventh postoperative day for more than $86 \%$ of patients with recurrent CD and $97.4 \%$ of those with de novo $\mathrm{CD}$. These normalization rates were durable at 12 months (Table 4).

\section{ACTH-Secreting Tumors}

\section{Surgical Pathology}

Pathological examination of samples collected during surgery revealed $\mathrm{CD}$ and $\mathrm{ACTH}$-positive staining tumors in $62(75.6 \%)$ of the 82 patients. There were 14 patients (17.1\%) with SCA. Atypical adenomas were found in 14 patients (17.1\%): 7 (13.7\%) of 51 patients with de novo and $7(22.6 \%)$ of 31 patients with recurrent tumors. Patients with CD and SCA were also immunohistochemically positive for other hormones: 15 adenomas (18.3\%) for prolactin, 13 (15.9\%) for growth hormone, 6 (7.3\%) for follicle-stimulating hormone, 8 (9.8\%) for luteinizing hormone, and $5(6.1 \%)$ for thyroid-stimulating hormone. The mean MIB-1 labeling index was 2.9\% (range 1\%-20\%); no statistical difference was found between those undergoing their first or second operations. The MIB-1 labeling 
TABLE 1. Preoperative characteristics of patients with CD and SCA

\begin{tabular}{|c|c|c|}
\hline Characteristic & Patients w/ CD & Patients w/ SCA \\
\hline No. of patients & 68 & 14 \\
\hline Mean age, yrs (range) & $38.7(8-67)$ & $51.6(27-70)$ \\
\hline \multicolumn{3}{|l|}{ Sex, no. $(\%)$} \\
\hline $\mathrm{F}$ & $48(70.6)$ & $7(50.0)$ \\
\hline $\mathrm{M}$ & $20(29.4)$ & $7(50.0)$ \\
\hline Recurrence, no. (\%) & $29(42.6)$ & $2(14.3)$ \\
\hline \multicolumn{3}{|l|}{ Cushing's syndrome symptoms, no. (\%) } \\
\hline Weight gain & $53(77.9)$ & $4(28.6)$ \\
\hline Centripetal fat deposition & $42(61.8)$ & $2(14.3)$ \\
\hline Muscle wasting & $16(23.5)$ & $1(7.1)$ \\
\hline Skin changes* & $29(42.6)$ & $0(0.0)$ \\
\hline Hair changes $†$ & $24(35.3)$ & $1(7.1)$ \\
\hline Hyperpigmentation & $9(13.2)$ & $0(0.0)$ \\
\hline Acne & $7(10.3)$ & $0(0.0)$ \\
\hline Hypertension & $31(45.6)$ & $6(42.9)$ \\
\hline Osteoporosis & $13(19.1)$ & $2(14.3)$ \\
\hline Growth retardation & $9(13.2)$ & $0(0.0)$ \\
\hline Anxiety & $14(20.6)$ & $1(7.1)$ \\
\hline Mood changes $\ddagger$ & $20(29.4)$ & $1(7.1)$ \\
\hline Cognitive dysfunction§ & $8(11.8)$ & $0(0.0)$ \\
\hline Sexual dysfunction & $8(11.8)$ & $3(21.4)$ \\
\hline Fertility problems & $2(2.9)$ & $0(0.0)$ \\
\hline Dysmenorrhea/amenorrheaף & $19(39.5)$ & $2(16.7)$ \\
\hline \multicolumn{3}{|l|}{ General symptoms, no. (\%) } \\
\hline Headache & $23(33.8)$ & $10(71.4)$ \\
\hline Visual disturbance & $16(23.5)$ & $9(64.3)$ \\
\hline \multicolumn{3}{|l|}{$\mathrm{CN}$ paresis } \\
\hline Oculomotor (CN III) & $2(2.9)$ & $1(7.1)$ \\
\hline Abducens (CN VI) & $0(0.0)$ & $0(0.0)$ \\
\hline Pituitary tumor apoplexy & $1(1.5)$ & $4(28.6)$ \\
\hline Hypopituitarism** & $6(8.8)$ & $1(7.1)$ \\
\hline Galactorrhea & $4(5.9)$ & $0(0.0)$ \\
\hline Fatigue & $36(52.9)$ & $8(57.1)$ \\
\hline Incidental & $0(0.0)$ & $1(7.1)$ \\
\hline \multicolumn{3}{|l|}{ Preop hormone replacement therapy, no. (\%) } \\
\hline Thyroid hormone & $6(8.8)$ & $4(28.6)$ \\
\hline Testosterone & $0(1.5)$ & $0(0.0)$ \\
\hline Growth hormone†† & $1(1.5)$ & $0(0.0)$ \\
\hline Desmopressin†† & $1(1.5)$ & $0(0.0)$ \\
\hline Diabetes medication & $45(67.3)$ & $8(59.3)$ \\
\hline Adrenalectomy, no. (\%) & $1(1.5)$ & $0(0.0)$ \\
\hline Mean preop serum cortisol, $\mu \mathrm{g} / \mathrm{dl}$ (range) & $22.1(18.9-54.4)$ & $12.7(2.3-20.6)$ \\
\hline Median follow-up time, mos (range) & $12.0(3-48)$ & $24.0(3-69)$ \\
\hline
\end{tabular}

$\mathrm{CN}=$ cranial nerve.

* Bruising, abdominal striae, or thinning.

† Alopecia capitis or facial/truncal hirsutism.

‡ Depression, irritability, or impulsivity.

$\S$ Memory problems or inattention.

II In 48 women.

** One or more derangements in other pituitary axes.

†† Replacement after surgery. 
TABLE 2. Preoperative MRI characteristics of patients with CD and SCA

\begin{tabular}{lcc}
\hline & \multicolumn{2}{c}{ No. of Patients (\%) } \\
\cline { 2 - 3 } Tumor Characteristic & w/ CD & w/ SCA \\
\hline Microadenoma & $60(88.2)$ & $6(42.9)$ \\
\hline Macroadenoma & $2(2.9)$ & $8(57.1)$ \\
\hline Invasive & $7(10.3)$ & $1(7.1)$ \\
\hline Cystic & $2(2.9)$ & $1(7.1)$ \\
\hline Parasellar & $9(13.2)$ & $0(0.0)$ \\
\hline Suprasellar & $2(2.9)$ & $2(14.2)$ \\
\hline No abnormalities & $6(8.8)$ & $0(0.0)$ \\
\hline
\end{tabular}

index is the fraction of tumor cells that are labeled by $\mathrm{Ki}$ 67 and is used as an index of proliferation. Hyperplasia was diagnosed in 8 patients $(9.8 \%)$, and significantly more of these patients (7 [22.6\%] of 31) underwent a second operation than underwent only a first operation $(1[2.0 \%]$ of $51 ; p<0.05$ ) (Table 5). Operative specimens were found to be normal gland in 6 patients $(7.3 \%)$.

\section{Complications}

Minor Complications. The overall rate of minor complications (for CD and SCA patients) was $35.4 \%$. Minor complications occurred in $24 \mathrm{CD}$ patients $(35.3 \%)$ and 5 SCA patients (35.7\%). Transient symptomatic SIADH developed in $3 \mathrm{CD}$ patients (4.4\%) and no SCA patients. Transient DI developed in $16 \mathrm{CD}$ patients $(23.5 \%)$ and in a comparable percentage $(n=3,21.4 \%)$ of SCA patients. However, transient DI was more likely to develop in CD patients after a second operation $(\mathrm{n}=11,37.9 \%)$ than after a first operation $(\mathrm{n}=5,12.8 \%, \mathrm{p}<0.05)$. Postoperative epistaxis developed in $1 \mathrm{CD}$ patient, and sinus mucoceles developed in 2. Transient postoperative visual blurring, which resolved spontaneously within 7 days, was reported by 1 patient; wound dehiscence occurred at the abdominal

\section{TABLE 3. Perioperative characteristics of patients with CD and} SCA

\begin{tabular}{lcc}
\hline \multirow{2}{*}{ Characteristic } & \multicolumn{2}{c}{ No. of Patients } \\
\cline { 2 - 3 } & w/ CD & w/ SCA \\
\hline Technology used, no. (\%) & $10(14.7)$ & $0(0.0)$ \\
\hline Microscope & $66(97.1)$ & $14(100.0)$ \\
\hline Endoscope & $4(7.6)$ & $3(12.5)$ \\
\hline Both & & \\
\hline Intraop, no. (\%) & $34(50.0)$ & $8(57.1)$ \\
\hline Fat graft/CSF leak & $28(41.2)$ & $5(35.7)$ \\
\hline Nasal packing & $1(1.3)$ & $0(0.0)$ \\
\hline Lumbar drain & & \\
\hline Postop & $195(40.1)$ & $201(35.9)$ \\
\hline Mean op time, mins (SD) & $16(23.5)$ & $1(7.1)$ \\
\hline ICU admission, no. (\%) & $3.3(1.0)$ & $2.8(1.1)$ \\
\hline Mean hospital stay, days (SD) & $64(94.1)$ & $11(78.6)$ \\
\hline GTR, no. (\%) &
\end{tabular}

$\mathrm{ICU}=$ intensive care unit. fat graft site in 1 patient; and self-limiting aseptic meningitis, which was treated symptomatically with steroids (Table 6), occurred in 1 patient.

Major Complications. The overall rate of major complications was $8.5 \%(\mathrm{n}=7)$. All permanent morbidity was associated with DI $(\mathrm{n}=5,6.1 \%)$. Permanent DI developed in $4 \mathrm{CD}$ patients $(5.9 \%)$ and 1 SCA patient (7.1\%). For $1 \mathrm{CD}$ patient, an intraoperative carotid artery injury required endovascular sacrifice of the injured artery, but the patient remained neurologically intact. For $1 \mathrm{CD}$ patient, major postoperative epistaxis required another operative procedure to achieve hemostasis. For another CD patient, minor postoperative epistaxis was treated effectively with topical vasoconstrictors and nasal packing. No postoperative CSF leak, permanent visual loss, or deep vein thrombosis was reported for any patient (Table 6).

\section{Discussion}

Transsphenoidal surgery is a safe and effective treatment for patients with CD and SCA. $5,13,16,41,45,49,50,53-55,58,61,63$ Rates of GTR tend to be high in terms of diagnostic pathology ${ }^{16,42,51}$ and higher among patients with CD than with SCA. ${ }^{47}$ This trend is probably associated with the diminutive size of CD adenomas compared with SCAs as well as the invasive nature of SCAs in general. In the series reported here, $88.2 \%$ of CD patients harbored microadenomas, and rates of GTR were $94.1 \%$. In comparison, $57.1 \%$ of SCA patients had macroadenomas, and rates of GTR were lower (78.6\%.) Of note, only 1 patient had an invasive SCA, less than what has historically been reported in comparable series. ${ }^{47}$ In a series of 23 patients with SCA, Scheithauer et al. found that all tumors were macroadenomas, $87 \%$ with suprasellar extension and $61 \%$ with radiographic evidence of cystic change..$^{47}$ In the series reported here, the tumor was discovered incidentally for 1 SCA patient, and tumors in 6 SCA patients were classified as microadenomas, which could account for the low incidence of invasion. For the remaining 7 SCA patients, 3 tumors $(42.8 \%)$ were classified as cystic, suprasellar, or invasive.

Complications in patients undergoing a transsphenoidal operative procedure are rare but important to anticipate..$_{1,50,55,66}$ The reported postoperative mortality rate is low, $0.4-2.0 \%, 41,50,55,66$ and none of the patients reported in our series died. Among patients undergoing transsphenoidal surgery for pituitary adenomas in general, the rate range of morbid complications is $3.3 \%-9.3 \% \%^{3,7,27}$ but tends to be higher among patients undergoing similar operative treatment for $\mathrm{CD}$ (range 9\%-15\%). $1,7,11,36,41,50,54,55,58,63$ In our series, the overall rate of minor complications (among CD and SCA patients) was $35.4 \%$, and the rate of major complications was $8.5 \%$. All permanent morbidity was associated with DI $(\mathrm{n}=5,6.1 \%)$; when patients with DI were excluded from analysis, the overall rate of major complications was $2.4 \%$ (Table 6).

In general, patients undergoing transsphenoidal surgery are at greater risk for complications if they harbor macroadenomas or if the surgery is a repeat operation for recurrent disease. ${ }^{1,7,30,36} \mathrm{We}$ found that patients undergoing an operation for recurrent disease were 3.3 times more 
TABLE 4. Postoperative normalization of serum cortisol levels in 68 patients with CD

\begin{tabular}{|c|c|c|c|}
\hline Perioperative Day & Serum ACTH Cortisol (pg/ml)* & Serum Cortisol Level ( $\mu \mathrm{g} / \mathrm{dl})$ & Normal Cortisol Level, no. (\%)† \\
\hline \multicolumn{4}{|l|}{ 1st TSS, 39 patients } \\
\hline Mean preop (range) & $169(11-3351)$ & $23.4(18.1-75.6)$ & $13(33.3)$ \\
\hline POD1‡ & & $12.5(0.8-54.4)$ & $32(82.1)$ \\
\hline POD2 $\ddagger$ & & $11.4(0.8-29.6)$ & $35(89.7)$ \\
\hline POD7 $\ddagger$ & & $10.9(1.0-27.9)$ & $38(97.4)$ \\
\hline 12 mos postop & $69(5-88)$ & $9.0(0.8-36.8)$ & $37(94.9)$ \\
\hline \multicolumn{4}{|l|}{ 2nd TSS, 29 patients } \\
\hline Mean preop (range) & $118(10-887)$ & $20.3(17.1-36.0)$ & $9(31.3)$ \\
\hline POD1‡ & & $15.4(0.6-40.4)$ & $21(72.4)$ \\
\hline POD2 $\ddagger$ & & $11.9(0.6-28.5)$ & $26(89.7)$ \\
\hline POD7 $\ddagger$ & & $12.8(0.8-39.5)$ & $25(86.2)$ \\
\hline 12 mos postop & $114(5-982)$ & $11.3(0.1-81.1)$ & $25(86.2)$ \\
\hline
\end{tabular}

likely to experience a complication than were those undergoing surgery for de novo disease $(\mathrm{OR} 3.3, \mathrm{p}=0.015)(\mathrm{Ta}-$ ble 6). However, this association was driven by transient DI, and when these patients were removed from the analysis, there was no longer a significant difference between the 2 groups. There does, however, seem to be an association between repeat surgery and development of transient DI in CD patients (OR 3.1, p = 0.04) (Table 6).

Use of endoscopic transsphenoidal pituitary surgery is slowly but steadily replacing use of microscopic approaches. The overall rates of complications with microscopic $^{8,16,18,50,56}$ and endoscopic approaches ${ }^{14,44,67,73,77,79}$ for treatment of CD seem to be similar. The best study for comparing the microscopic approach to the current endoscopic approach was published in 1999 by the senior author (E.R.L.). ${ }^{50}$ Among 105 patients with CD in that study (the historical series), the mortality rate was $0.9 \%$, and the permanent morbidity rate was $1.8 \%$. The overall rate of complications in that series of patients was $13.3 \%$, compared with $35 \%$ in the series reported here. Most of the CD complications among patients who underwent the endoscopic approach were associated with transient natremia imbalance (79\% of minor complications). Incidence of permanent DI was higher among patients in our series (5.8\%) than among those who underwent the microscopic approach for CD (1.0\%). It is possible that greater visualization through endoscopy has led to greater manipulation of the pituitary gland and thus higher rates of postoperative dysnatremia. The endoscopic approach used in this series resulted in no nasal septal perforations compared with 2 perforations among patients in the historical series who underwent the microscopic approach. Incidence of

TABLE 5. Pathology of tissue surgically collected from patients with CD or SCA who underwent transsphenoidal surgery

\begin{tabular}{lccc}
\hline & & No. of Patients $(\%)$ & \\
\cline { 2 - 4 } Characteristic & 1st TSS $(\mathrm{n}=51)$ & 2nd TSS $(\mathrm{n}=31)$ & All $(\mathrm{n}=82)$ \\
\hline Immunohistochemistry & & & \\
\hline ACTH $(\mathrm{CD})$ & $35(68.6)$ & $27(87.1)$ & $14(17.1)$ \\
\hline Silent ACTH & $12(23.5)$ & $2(6.5)$ & $6(7.3)$ \\
\hline Follicle-stimulating hormone & $2(3.9)$ & $4(12.9)$ & $8(9.8)$ \\
\hline Luteinizing hormone & $4(7.8)$ & $4(12.9)$ & $13(15.9)$ \\
\hline Human growth hormone & $8(15.7)$ & $5(16.1)$ & $15(18.5)$ \\
\hline Prolactin & $10(20.0)$ & $5(16.1)$ & $5(6.1)$ \\
\hline Thyroid-stimulating hormone & $2(3.9)$ & $3(9.7)$ & $8(17.1)$ \\
\hline Atypical & $7(13.7)$ & $7(22.6)$ & $6(7.3)$ \\
\hline Hyperplasia & $1(2.0)$ & $2(6.4)$ & $2.9(1.0-20.0)$ \\
\hline Normal gland & $4(7.8)$ & $2.6(1.0-15.6)$ & \\
\hline Mean proliferation index (MIB), \% (range) $\dagger$ & $3.1(1.0-20.0)$ & & \\
\hline$*$ & & & \\
\hline
\end{tabular}


TABLE 6. Postoperative complications in patients with CD (categorized by first or second operation) and SCA*

\begin{tabular}{|c|c|c|c|c|}
\hline \multirow[b]{2}{*}{ Complication } & \multicolumn{2}{|c|}{ Patients w/ CD } & \multirow[b]{2}{*}{ All CD Patients ( $n=68)$} & \multirow[b]{2}{*}{ Patients w/ SCA $(n=14)$} \\
\hline & 1st TSS ( $n=39)$ & 2nd TSS $(n=29)$ & & \\
\hline \multicolumn{5}{|l|}{ Minor } \\
\hline Transient symptomatic SIADH & $1(2.6)$ & $2(6.9)$ & $3(4.4)$ & $0(0.0)$ \\
\hline Transient DI & $5(12.8)$ & $11(37.9)$ & $16(23.5) \dagger$ & $3(21.4)$ \\
\hline Epistaxis & $0(0.0)$ & $1(3.4)$ & $1(1.3)$ & $0(0.0)$ \\
\hline Sinus-related (mucocele) & $1(2.6)$ & $1(3.4)$ & $2(2.7)$ & $0(0.0)$ \\
\hline Deep vein thrombosis & $0(0.0)$ & $0(0.0)$ & $0(0.0)$ & $0(0.0)$ \\
\hline Transient visual impairment & $0(0.0)$ & $0(0.0)$ & $0(0.0)$ & $1(7.1)$ \\
\hline Abdominal wound dehiscence & $0(0.0)$ & $0(0.0)$ & $0(0.0)$ & $1(7.1)$ \\
\hline Aseptic meningitis & $1(2.6)$ & $0(0.0)$ & $1(1.3)$ & $0(0.0)$ \\
\hline 30-day readmission & $1(2.2)$ & $0(0.0)$ & $1(1.3)$ & $0(0.0)$ \\
\hline Total & & & $24(35.3)$ & $5(35.7)$ \\
\hline \multicolumn{5}{|l|}{ Major } \\
\hline Permanent DI & $1(2.6)$ & $3(10.3)$ & $4(5.9)$ & $1(7.1)$ \\
\hline Postop CSF leak & $0(0.0)$ & $0(0.0)$ & $0(0.0)$ & $0(0.0)$ \\
\hline Bacterial meningitis & $0(0.0)$ & $0(0.0)$ & $0(0.0)$ & $0(0.0)$ \\
\hline Reoperation (epistaxis) & $0(0.0)$ & $1(3.4)$ & $1(1.5)$ & $0(0.0)$ \\
\hline Carotid artery injury & $1(2.6)$ & $0(0.0)$ & $1(1.5)$ & $0(0.0)$ \\
\hline Permanent visual impairment & $0(0.0)$ & $0(0.0)$ & $0(0.0)$ & $0(0.0)$ \\
\hline Total & & & $6(8.8)$ & $1(7.1)$ \\
\hline
\end{tabular}

deep vein thrombosis was higher among patients undergoing microscopic transsphenoidal surgery in the historical series $(n=4,3.8 \%)$ than among those undergoing the endoscopic approach in our series $(n=0)$. As a result of his experience with deep vein thrombosis, and after publishing the former study in 1999, the senior author began giving aspirin $(81 \mathrm{mg})$ to patients 1 day after transsphenoidal surgery. The absence of deep vein thrombosis among patients in the current series probably reflects this change in treatment strategy.

\section{Syndrome of Inappropriate Antidiuretic Hormone Secretion}

Symptomatic hyponatremia is a reported complication of transsphenoidal surgery $(2.1 \%-9.0 \%) \cdot{ }^{17,19,25,40,60} \mathrm{CD}$ patients in particular seem to be at the same risk for postoperative development of symptomatic hyponatremia. Semple and Laws reported a 5.7\% incidence of postoperative hyponatremia in CD patients. ${ }^{50}$ We report a $4.4 \%(n=3)$ rate of transient symptomatic SIADH in CD patients. Symptomatic, delayed hyponatremia associated with SIADH is poorly understood but is thought to be associated with postoperative release of stored antidiuretic hormone from traumatized nerve terminals within the pituitary gland. ${ }^{17,25,39,40,60}$ Other factors that can drive postoperative hyponatremia include cerebral salt wasting, excessive fluid intake, and low dietary sodium intake. ${ }^{39}$

\section{Diabetes Insipidus}

One of the most common forms of transient perturbation of fluid homeostasis after transsphenoidal procedures is central DI. The reported overall incidence of postoperative transient DI is $8.7 \%-18.3 \%$; persistent DI requiring long-term treatment with desmopressin develops in $2.0 \%-$ $12.4 \%$ of patients. ${ }^{26,36,48}$ Patient and operative factors that have been associated with the development of permanent DI include intraoperative CSF leakage and resection of a craniopharyngioma and/or Rathke's cleft cyst. ${ }^{12,26,32,35,48}$ Transient postoperative DI has been associated with repeated operation for recurrent disease, CD, and microadenoma. ${ }^{36,48}$

Among the patients in our series, transient postoperative DI requiring treatment with desmopressin during hospitalization developed in $16 \mathrm{CD}$ patients $(23.5 \%)$. Undergoing a second surgery for recurrence was found to be a significant predictor of development of this condition in CD patients $(\mathrm{n}=11,37.9 \%)$ compared with CD patients undergoing their first operation $(\mathrm{n}=5,12.8 \%, \mathrm{p}<0.05)$. Permanent DI developed in 4 CD patients (5.9\%), among whom all had microadenomas, 2 had an intraoperative CSF leak, and 3 were undergoing their second operation. Transient postoperative DI developed in 3 (21.4\%) SCA patients; permanent DI later developed in 1 of these patients.

Apart from the potential neurological sequelae of untreated DI, many patients are at risk for readmission to the hospital for stabilization and treatment of hypernatremia. In the series reported here, the only person readmitted was a $\mathrm{CD}$ patient with DI.

\section{Carotid Artery Injury}

One of the major complications associated with the en- 
donasal endoscopic transsphenoidal procedure is injury to the ICA, which can be one of the most devastating complications for the patient. ${ }^{15}$ Injuries to the ICA have been associated with both microscopic and endoscopic endonasal approaches, and incidence of injury ranges from $0.4 \%$ to $3.8 \% .^{1,57}$ The consequences of ICA injury can range from being innocuous to fatal. Potential vascular sequelae of ICA violation include formation of pseudoaneurysms, carotid cavernous fistulas, postoperative vasospasm, and even vascular occlusion resulting in clinical ischemia and stroke. A recent meta-analysis highlighted vascular injury as an uncommon but important complication of transsphenoidal approaches. ${ }^{1,29}$

In the series reported here, only $1 \mathrm{CD}$ patient experienced intraoperative injury to the cavernous carotid artery. The hemorrhage was tamponaded, and the patient was immediately transferred to the endovascular suite for a diagnostic angiogram and subsequent sacrifice of the affected artery. The patient recovered well from the complication, without any neurological deficit. As of the 3-year followup examination, no untoward, delayed intracranial complication had developed.

\section{Infections}

Infections after transsphenoidal surgery are rare. The 3 most common forms of postoperative infection are meningitis, sinusitis, and dehiscence of the abdominal fat graft wound. Bacterial meningitis occurs in $0.4 \%-1.8 \%$ of transsphenoidal surgery patients. ${ }^{2,3,7,24,43} \mathrm{CD}$ patients are known to be prone to infection before surgery, but rates of postoperative meningitis among these patients seem to be similar to rates among patients with other pituitary tumors. ${ }^{43}$ No bacterial meningitis developed in any patient in our series, but aseptic meningitis developed in 1 patient. Symptoms resolved after oral administration of corticosteroids.

In patients who undergo an abdominal fat graft, the abdominal wound can be at risk for dehiscence, hematoma formation, and infection. This occurrence is rare, however, even in large series. ${ }^{21}$ In 1 SCA patient in our series, an abdominal wound dehisced, and the patient was given a short course of oral antibiotics, with successful resolution.

\section{Vision Changes}

Visual loss after transsphenoidal surgery can result from direct neural injury, devascularization, or compression. More specifically, proximal, postoperative causes of visual impairment are thought to be direct injury to (or devascularization of) any portion of the optic apparatus, an occult fracture of the bony orbit that causes compression of neural elements, a postoperative hematoma compressing the optic chiasm, cerebral vasospasm causing hemodynamic ischemia, and/or prolapse of the optic chiasm into an empty sella.

The range of visual loss after transsphenoidal surgery

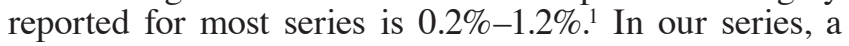
transient, subjective decrease in visual acuity was experienced by 1 patient; neuroophthalmological evaluation on postoperative Day 2 revealed normal efferent and afferent function. The patient's visual blurriness was attributed to blood pressure fluctuations and endocrine derangement and resolved without treatment 1 week after surgery.

\section{Epistaxis}

Epistaxis after transsphenoidal surgery can be severe and can have a substantial detrimental effect on patient outcomes. Epistaxis can be either immediate or delayed; delayed epistaxis occurs an average of 10 days after surgery., ${ }^{2,9}$ Immediate postoperative epistaxis has been associated with ICA injury and acute postoperative hypertension; delayed epistaxis has been associated with anterior ethmoidal artery injury and postoperative anticoagulation. ${ }^{9}$ Treatment for epistaxis depends on its severity and can range from bedside nasal packing to endovascular embolization and/or reoperative exploration. ${ }^{9}$

In our series, minor epistaxis in $1 \mathrm{CD}$ patient was successfully treated with bedside nasal packing. Spontaneous epistaxis occurred in another CD patient while exercising 5 weeks after the operative procedure. The patient sought care at the emergency room and was taken to the operating room for endoscopic exploration. A small hemorrhagic source from the inferior margin of the septectomy was subsequently cauterized and overlain with Surgicel (Ethicon Incorporated, Johnson \& Johnson). The patient was discharged without further issue. Neither patient suffered any long-term adverse sequelae of epistaxis.

\section{Sinus Mucocele}

Sinus-related complications after transsphenoidal surgery are uncommon; incidence is $1.2 \%-6.2 \% .4,31$ Sinusitis and/or sinus mucoceles can form postoperatively and are thought to be associated with infection, necrosis of fat graft, remnant bone fragments, and mechanical/thermal trauma to the mucosa. ${ }^{31} \mathrm{Lu}$ et al. ${ }^{31}$ correlated the size of the bony window opened in the face of the sphenoid sinus with postoperative sinus complications. They reported higher incidence of sinus-related complications among patients with small sphenoidotomies, decreased frequency of routine postoperative nasal care, and postoperative foreign debris accumulation in the sphenoid sinus. For avoiding these complications, they recommended removal of at least two-thirds of the sphenoid face, regular nasal hygiene, and meticulous removal of bony fragments. ${ }^{31}$ For patients with rhinosinusitis/mucocele that is refractory to medical management, the next management step is early surgical drainage. If these complications are left untreated or undertreated, they can progress into fulminant bacterial meningitis.

In our series, nasal mucoceles, without overt sinusitis, developed in 2 CD patients. For both patients, the mucoceles resolved with regular nasal hygiene with saline spray and without any further procedures.

\section{CSF Leak}

A CSF leak occurs as a postoperative complication in $0.6 \%-10 \%$ of transsphenoidal surgery patients. ${ }^{2,3,22,57} \mathrm{Re}-$ ported predictors of postoperative CSF leakage include large tumors, invasion of sella diaphragm, craniopharyngioma and Rathke's cleft cyst pathologies, tumor adherence, presence of arachnoid diverticulum, suprasellar tumor extension, and extended skull-base approaches. ${ }^{19,22,57}$ Chee et al. reported CSF leakage rates of 7.4\% among patients with CD exclusively. ${ }^{6}$ 
With the proper identification and intraoperative attention, the rate of postoperative CSF leakage can be drastically reduced. Among patients in our series, no postoperative CSF leaks occurred. However, weeping intraoperative CSF leaks were suspected in 42 patients (51.2\%), and therefore for each patient, the sella was packed with an abdominal fat graft. A lumbar drain was placed in 1 patient with a recurrent, invasive tumor after induction of anesthesia and before surgery. An intrathecal drain was used for the injection of air to encourage intraoperative tumor subsidence and for postoperative CSF diversion to treat an anticipated, generous leak. After tumor resection, a sellaplasty with an epidural synthetic plate was fashioned to the specifications of the sellar opening. A sellaplasty can also be fashioned from the nasal septum. Gelfoam (Pfizer) pledgets were then laid over the synthetic plate so that it was not in direct contact with sphenoid sinus air.

\section{Deep Venous Thrombosis}

Although patients undergoing transsphenoidal operations are at low risk for the development of deep vein thrombosis (2.5\%), the risk for those with CD is reportedly higher (range 5.5\%-5.9\%). ${ }^{50}$ Overall, the risk for development of venous thromboembolism is more than 10 -fold higher for patients with hypercortisolemia than for their age-matched counterparts without hypercortisolemia. ${ }^{62}$ The hypercoagulable state in hypercortisolemic patients is thought to be associated with increased procoagulant production, coagulation cascade activation, and impaired fibrinolytic capacity. The result of these cascade perturbations is a shortened activated partial thromboplastin time and a subsequently increased time required for thrombolysis. ${ }^{62}$

Of note, deep vein thrombosis was not diagnosed for any patients in our series. Before induction of anesthesia, all patients were fitted with bilateral, lower extremity sequential compression devices, which they wore for the remainder of their hospital stay. In conjunction with these devices, CD patients also received aspirin $(81 \mathrm{mg})$ starting on postoperative Day 1 and continuing for 6 weeks. All patients were encouraged to dorsiflex/plantarflex their feet while in bed and were mobilized the day after surgery. No patient received heparin products for chemoprophylaxis against formation of deep vein thrombosis. This algorithm has essentially eliminated symptomatic postoperative deep vein thrombosis in $\mathrm{CD}$ patients.

This study has a number of limitations. First, it was a retrospective chart review and, as such, is subject to all biases attendant to this study design. Second, the definition of $\mathrm{CD}$ remission is variable, and the data reported here represent serum cortisol normalization, which could artificially inflate remission rates in the short term because patients with residual disease could have serum cortisol levels in the "normal" range. Third, this patient population may not be representative of the other CD and SCA populations. Many of these patients are referred for consultation because of diagnostic ambiguity, anatomical complexity, or residual/recurrent disease; therefore, their treatment results may not reflect the outcomes of other patients.

\section{Conclusions}

Transsphenoidal surgery is the treatment of choice for patients with CD or SCA. Recent advances in endoscopic technology and increasing surgeon comfort with this technology are making transsphenoidal procedures safer, faster, and more effective. Permanent morbidity is rare, and serious complications, although uncommon, can be managed successfully.

\section{References}

1. Ammirati M, Wei L, Ciric I: Short-term outcome of endoscopic versus microscopic pituitary adenoma surgery: a systematic review and meta-analysis. J Neurol Neurosurg Psychiatry 84:843-849, 2013

2. Berker M, Hazer DB, Yücel T, Gürlek A, Cila A, Aldur M, et al: Complications of endoscopic surgery of the pituitary adenomas: analysis of 570 patients and review of the literature. Pituitary 15:288-300, 2012

3. Black PM, Zervas NT, Candia GL: Incidence and management of complications of transsphenoidal operation for pituitary adenomas. Neurosurgery 20:920-924, 1987

4. Cappabianca P, Cavallo LM, Colao A, de Divitiis E: Surgical complications associated with the endoscopic endonasal transsphenoidal approach for pituitary adenomas. J Neurosurg 97:293-298, 2002

5. Chandler WF, Schteingart DE, Lloyd RV, McKeever PE, Ibarra-Perez G: Surgical treatment of Cushing's disease. J Neurosurg 66:204-212, 1987

6. Chee GH, Mathias DB, James RA, Kendall-Taylor P: Transsphenoidal pituitary surgery in Cushing's disease: can we predict outcome? Clin Endocrinol (Oxf) 54:617-626, 2001

7. Ciric I, Ragin A, Baumgartner C, Pierce D: Complications of transsphenoidal surgery: results of a national survey, review of the literature, and personal experience. Neurosurgery 40:225-237, 1997

8. Ciric I, Zhao JC, Du H, Findling JW, Molitch ME, Weiss RE, et al: Transsphenoidal surgery for Cushing disease: experience with 136 patients. Neurosurgery 70:70-81, 2012

9. De Los Reyes KM, Gross BA, Frerichs KU, Dunn IF, Lin N, Rincon-Torroella J, et al: Incidence, risk factors and management of severe post-transsphenoidal epistaxis. J Clin Neurosci [epub ahead of print], 2014

10. Dehdashti AR, Gentili F: Current state of the art in the diagnosis and surgical treatment of Cushing disease: early experience with a purely endoscopic endonasal technique. Neurosurg Focus 23(3):E9, 2007

11. Dekkers OM, Horváth-Puhó E, Jørgensen JO, Cannegieter SC, Ehrenstein V, Vandenbroucke JP, et al: Multisystem morbidity and mortality in Cushing's syndrome: a cohort study. J Clin Endocrinol Metab 98:2277-2284, 2013

12. DeKlotz TR, Chia SH, Lu W, Makambi KH, Aulisi E, Deeb $\mathrm{Z}$ : Meta-analysis of endoscopic versus sublabial pituitary surgery. Laryngoscope 122:511-518, 2012

13. Fahlbusch R, Buchfelder M, Müller OA: Transsphenoidal surgery for Cushing's disease. J R Soc Med 79:262-269, 1986

14. Fardet L, Fève B: Systemic glucocorticoid therapy: a review of its metabolic and cardiovascular adverse events. Drugs 74:1731-1745, 2014

15. Gardner PA, Tormenti MJ, Pant H, Fernandez-Miranda JC, Snyderman CH, Horowitz MB: Carotid artery injury during endoscopic endonasal skull base surgery: incidence and outcomes. Neurosurgery 73 (2 Suppl Operative):ons261ons 270,2013

16. Hammer GD, Tyrrell JB, Lamborn KR, Applebury CB, Hannegan ET, Bell S, et al: Transsphenoidal microsurgery for Cushing's disease: initial outcome and long-term results. J Clin Endocrinol Metab 89:6348-6357, 2004 
17. Hensen J, Henig A, Fahlbusch R, Meyer M, Boehnert M, Buchfelder M: Prevalence, predictors and patterns of postoperative polyuria and hyponatraemia in the immediate course after transsphenoidal surgery for pituitary adenomas. Clin Endocrinol (Oxf) 50:431-439, 1999

18. Honegger J, Schmalisch K, Beuschlein F, Kaufmann S, Schnauder G, Naegele T, et al: Contemporary microsurgical concept for the treatment of Cushing's disease: endocrine outcome in 83 consecutive patients. Clin Endocrinol (Oxf) 76:560-567, 2012

19. Jahangiri A, Wagner J, Han SW, Zygourakis CC, Han SJ, Tran MT, et al: Morbidity of repeat transsphenoidal surgery assessed in more than 1000 operations. J Neurosurg 121:6774, 2014

20. Jahangiri A, Wagner JR, Pekmezci M, Hiniker A, Chang EF, Kunwar S, et al: A comprehensive long-term retrospective analysis of silent corticotrophic adenomas vs hormone-negative adenomas. Neurosurgery 73:8-18, 2013

21. Jane JA Jr, Laws ER Jr: The surgical management of pituitary adenomas in a series of 3,093 patients. J Am Coll Surg 193:651-659, 2001

22. Jho HD: Endoscopic transsphenoidal surgery. J Neurooncol 54:187-195, 2001

23. Kageyama K, Oki Y, Nigawara T, Suda T, Daimon M: Review: Pathophysiology and treatment of subclinical Cushing's disease and pituitary silent corticotroph adenomas. Endocr J 61:941-948, 2014

24. Kaptain GJ, Kanter AS, Hamilton DK, Laws ER: Management and implications of intraoperative cerebrospinal fluid leak in transnasoseptal transsphenoidal microsurgery. Neurosurgery 68 (1 Suppl Operative):144-151, 2011

25. Kelly DF, Laws ER Jr, Fossett D: Delayed hyponatremia after transsphenoidal surgery for pituitary adenoma. Report of nine cases. J Neurosurg 83:363-367, 1995

26. Komotar RJ, Starke RM, Raper DM, Anand VK, Schwartz TH: Endoscopic endonasal compared with microscopic transsphenoidal and open transcranial resection of craniopharyngiomas. World Neurosurg 77:329-341, 2012

27. Krings JG, Kallogjeri D, Wineland A, Nepple KG, Piccirillo JF, Getz AE: Complications following primary and revision transsphenoidal surgeries for pituitary tumors. Laryngoscope [epub ahead of print], 2014

28. Lamos EM, Munir KM: Cushing disease: highlighting the importance of early diagnosis for both de novo and recurrent disease in light of evolving treatment patterns. Endocr Pract 20:945-955, 2014

29. Laws ER: Complications of transsphenoidal surgery: the shortcomings of meta-analysis. J Neurol Neurosurg Psychiatry 84:829, 2013

30. Laws ER Jr, Fode NC, Redmond MJ: Transsphenoidal surgery following unsuccessful prior therapy. An assessment of benefits and risks in 158 patients. J Neurosurg 63:823-829, 1985

31. Lu YJ, Chang CN, Pai PC, Wei KC, Chuang CC: Isolated sphenoid sinusitis or mucocele: a potential complication of endonasal transsphenoidal surgery. J Neurooncol 91:63-67, 2009

32. Mendelson ZS, Husain Q, Elmoursi S, Svider PF, Eloy JA, Liu JK: Rathke's cleft cyst recurrence after transsphenoidal surgery: a meta-analysis of 1151 cases. J Clin Neurosci 21:378-385, 2014

33. Mete O, Hayhurst C, Alahmadi H, Monsalves E, Gucer H, Gentili F, et al: The role of mediators of cell invasiveness, motility, and migration in the pathogenesis of silent corticotroph adenomas. Endocr Pathol 24:191-198, 2013

34. Mindermann T, Wilson CB: Age-related and gender-related occurrence of pituitary adenomas. Clin Endocrinol (Oxf) 41:359-364, 1994

35. Murad MH, Fernández-Balsells MM, Barwise A, Gallegos-
Orozco JF, Paul A, Lane MA, et al: Outcomes of surgical treatment for nonfunctioning pituitary adenomas: a systematic review and meta-analysis. Clin Endocrinol (Oxf) 73:777-791, 2010

36. Nemergut EC, Zuo Z, Jane JA Jr, Laws ER Jr: Predictors of diabetes insipidus after transsphenoidal surgery: a review of 881 patients. J Neurosurg 103:448-454, 2005

37. Netea-Maier RT, van Lindert EJ, den Heijer M, van der Eerden A, Pieters GF, Sweep CG, et al: Transsphenoidal pituitary surgery via the endoscopic technique: results in 35 consecutive patients with Cushing's disease. Eur J Endocrinol 154:675-684, 2006

38. Nieman LK, Biller BM, Findling JW, Newell-Price J, Savage MO, Stewart PM, et al: The diagnosis of Cushing's syndrome: an Endocrine Society Clinical Practice Guideline. J Clin Endocrinol Metab 93:1526-1540, 2008

39. Olson BR, Gumowski J, Rubino D, Oldfield EH: Pathophysiology of hyponatremia after transsphenoidal pituitary surgery. J Neurosurg 87:499-507, 1997

40. Olson BR, Rubino D, Gumowski J, Oldfield EH: Isolated hyponatremia after transsphenoidal pituitary surgery. J Clin Endocrinol Metab 80:85-91, 1995

41. Patil CG, Lad SP, Harsh GR, Laws ER Jr, Boakye M: National trends, complications, and outcomes following transsphenoidal surgery for Cushing's disease from 1993 to 2002. Neurosurg Focus 23(3):E7, 2007

42. Pouratian N, Prevedello DM, Jagannathan J, Lopes MB, Vance ML, Laws ER Jr: Outcomes and management of patients with Cushing's disease without pathological confirmation of tumor resection after transsphenoidal surgery. J Clin Endocrinol Metab 92:3383-3388, 2007

43. Prevedello DM, Pouratian N, Sherman J, Jane JA Jr, Vance ML, Lopes MB, et al: Management of Cushing's disease: outcome in patients with microadenoma detected on pituitary magnetic resonance imaging. J Neurosurg 109:751-759, 2008

44. Rajesh A: Silent corticotroph adenoma. Neurosurgery 73: E191-E192, 2013

45. Rees DA, Hanna FW, Davies JS, Mills RG, Vafidis J, Scanlon MF: Long-term follow-up results of transsphenoidal surgery for Cushing's disease in a single centre using strict criteria for remission. Clin Endocrinol (Oxf) 56:541-551, 2002

46. Reitmeyer M, Vance ML, Laws ER Jr: The neurosurgical management of Cushing's disease. Mol Cell Endocrinol 197:73-79, 2002

47. Scheithauer BW, Jaap AJ, Horvath E, Kovacs K, Lloyd RV, Meyer FB, et al: Clinically silent corticotroph tumors of the pituitary gland. Neurosurgery 47:723-730, 2000

48. Schreckinger M, Walker B, Knepper J, Hornyak M, Hong D, Kim JM, et al: Post-operative diabetes insipidus after endoscopic transsphenoidal surgery. Pituitary 16:445-451, 2013

49. Scott HW Jr, Liddle GW, Mulherin JL Jr, Mckenna TJ, Stroup SL, Rhamy RK: Surgical experience with Cushing's disease. Ann Surg 185:524-534, 1977

50. Semple PL, Laws ER Jr: Complications in a contemporary series of patients who underwent transsphenoidal surgery for Cushing's disease. J Neurosurg 91:175-179, 1999

51. Semple PL, Vance ML, Findling J, Laws ER Jr: Transsphenoidal surgery for Cushing's disease: outcome in patients with a normal magnetic resonance imaging scan. Neurosurgery 46:553-559, 2000

52. Shah NA, Urusova IA, D'Agnolo A, Colquhoun SD, Rosenbloom BE, Vener SL, et al: Primary hepatic carcinoid tumor presenting as Cushing's syndrome. J Endocrinol Invest 30:327-333, 2007

53. Sheehan JM, Lopes MB, Sheehan JP, Ellegala D, Webb KM, Laws ER Jr: Results of transsphenoidal surgery for Cushing's disease in patients with no histologically confirmed tumor. Neurosurgery 47:33-39, 2000 
54. Shimon I, Ram Z, Cohen ZR, Hadani M: Transsphenoidal surgery for Cushing's disease: endocrinological follow-up monitoring of 82 patients. Neurosurgery 51:57-62, 2002

55. Starke RM, Reames DL, Chen CJ, Laws ER, Jane JA Jr: Endoscopic transsphenoidal surgery for Cushing disease: techniques, outcomes, and predictors of remission. Neurosurgery 72:240-247, 2013

56. Swearingen B, Biller BM, Barker FG II, Katznelson L, Grinspoon S, Klibanski A, et al: Long-term mortality after transsphenoidal surgery for Cushing disease. Ann Intern Med 130:821-824, 1999

57. Tabaee A, Anand VK, Barrón Y, Hiltzik DH, Brown SM, Kacker A, et al: Endoscopic pituitary surgery: a systematic review and meta-analysis. J Neurosurg 111:545-554, 2009

58. Tindall GT, Herring CJ, Clark RV, Adams DA, Watts NB: Cushing's disease: results of transsphenoidal microsurgery with emphasis on surgical failures. J Neurosurg 72:363-369, 1990

59. Tong A, Jia A, Yan S, Zhang Y, Xie Y, Liu G: Ectopic cortisol-producing adrenocortical adenoma in the renal hilum: histopathological features and steroidogenic enzyme profile. Int J Clin Exp Pathol 7:4415-4421, 2014

60. Torales J, Halperin I, Hanzu F, Mora M, Alobid I, De Notaris $\mathrm{M}$, et al: Endoscopic endonasal surgery for pituitary tumors. Results in a series of 121 patients operated at the same center and by the same neurosurgeon. Endocrinol Nutr 61:410 416, 2014

61. Tritos NA, Biller BM: Cushing's disease. Handb Clin Neurol 124:221-234, 2014

62. van der Pas R, Leebeek FW, Hofland LJ, de Herder WW, Feelders RA: Hypercoagulability in Cushing's syndrome: prevalence, pathogenesis and treatment. Clin Endocrinol (Oxf) 78:481-488, 2013

63. Wagenmakers MA, Boogaarts HD, Roerink SH, Timmers
HJ, Stikkelbroeck NM, Smit JW, et al: Endoscopic transsphenoidal pituitary surgery: a good and safe primary treatment option for Cushing's disease, even in case of macroadenomas or invasive adenomas. Eur J Endocrinol 169:329-337, 2013

64. Webb KM, Laurent JJ, Okonkwo DO, Lopes MB, Vance ML, Laws ER Jr: Clinical characteristics of silent corticotrophic adenomas and creation of an internet-accessible database to facilitate their multi-institutional study. Neurosurgery 53:1076-1085, 2003

65. Yano S, Kawano T, Kudo M, Makino K, Nakamura H, Kai Y, et al: Endoscopic endonasal transsphenoidal approach through the bilateral nostrils for pituitary adenomas. Neurol Med Chir (Tokyo) 49:1-7, 2009

66. Zada G, Kelly DF, Cohan P, Wang C, Swerdloff R: Endonasal transsphenoidal approach for pituitary adenomas and other sellar lesions: an assessment of efficacy, safety, and patient impressions. J Neurosurg 98:350-358, 2003

\section{Author Contributions}

Conception and design: Smith, Laws. Acquisition of data: Smith, Hulou, Huang, Nery, Miranda de Moura. Analysis and interpretation of data: Smith, Hulou, Huang, Nery, Miranda de Moura. Drafting the article: Smith, Huang, Nery, Cote. Critically revising the article: Smith, Cote, Laws. Reviewed submitted version of manuscript: Smith, Cote, Laws. Approved the final version of the manuscript on behalf of all authors: Smith. Statistical analysis: Smith. Administrative/technical/material support: Smith, Hulou, Cote, Laws. Study supervision: Smith, Laws.

\section{Correspondence}

Timothy R. Smith, Pituitary/Neuroendoscopy Fellow, Brigham and Women's Hospital, 15 Francis St., PBB3, Boston, MA 02115. email: trsmith@partners.org. 